\title{
A Study on the Realization Mechanism of CSR in China
}

\author{
Maohua $\mathrm{Li}^{12}$ Ying Wang ${ }^{1}$ Zéman Zoltán ${ }^{3}$ \\ ${ }^{1}$ School of Business, Xi'an Siyuan University, \#28 Shui An Rd. Xi'an, China \\ ${ }^{2}$ Faculty of Economics and Social Sciences, Szent István University, Gödöllő, Hungary \\ ${ }^{3}$ Szent István University, Faculty of Economics and Social Sciences, Institute of Business Studies, \\ Páter Károly utca 1. H-2100, Gödöllö, Hungary
}

Keywords: CSR, realization mechanism, SPRE framework, China

Abstract: With the development of the CSR research, many research results come into our life. This paper wants to find a CSR realization mechanism based on the SPRE framework. This SPRE framework contains four layers: strategy layer, purpose layer, responsibility taker layer and execution layer. Through the four layers, all the social responsibility takers (government, corporate, investor and other stakeholder) should cooperate to realize the CSR. If all the responsibility takers can cooperate very well, it will come to Pareto Improvement, and at last the whole society will come to Pareto Optimality.

\section{Introduction}

Nowadays, as the development of economy, many problems happen, such as food safety, environmental problem. As a result of this phenomenon, people begin to focus on the corporate social responsibility (CSR), and many researching results have been got by scholars.

The research on CSR is very important, because it is the only one way that connects the government, corporate, investor in the capital market and other stakeholder. That is to say, CSR is the only way to help our society to sustainably develop, and it is also the basic and implacable base for human to survive. Without CSR, our society cannot be sustainable.

The academic research on CSR begins last century, there are lots of scholars are researching on CSR in the world now. They are focusing on different points of CSR. Some focus on the essence of CSR, and some focus on the relations of CSR, for instance, they do research on the relation between CSR and financial performance. And some scholars make researches on the social responsibility investment. They get many types of research results; however, nobody does any research on how to realize CSR.

In fact, the realization of CSR concerns many aspects, such as the government, corporate, investor and other stakeholder. So the realization of CSR needs them to cooperate with full energy. The purpose of this paper is to design the realization mechanism of CSR in China.

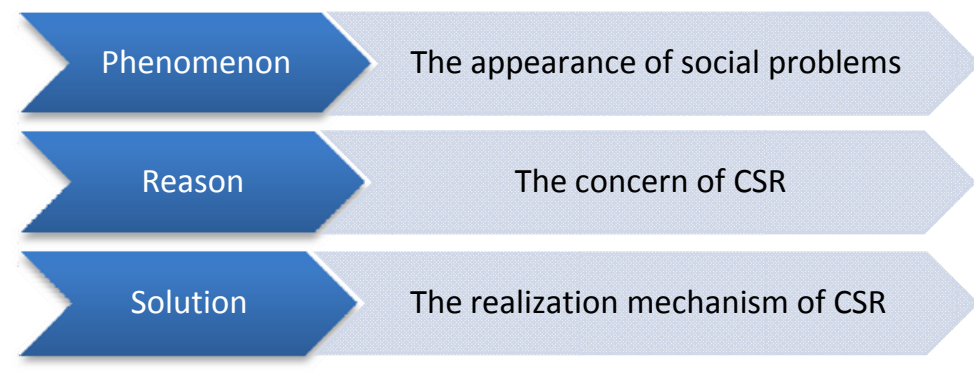

Figure 1. the research framework 


\section{The definition of CSR}

CSR is the responsibility taken by the main market players for the whole society. The organization as the main market player, should not only operate and get profit according to the market rules, but also take more non profitable responsibilities for the interests of the whole society. However, CSR is not the responsibility of corporate, so this paper wants to renew the definition of CSR from the following keywords.

\begin{tabular}{|c|c|}
\hline Who care? & Why care? \\
\hline What is profit? & CSR \\
\hline Invest or consume? \\
\hline
\end{tabular}

Figure 2. the definition of CSR

As shown in the figure 2, the definition of CSR concerns four key words.

-Who should take social responsibility?

When people talk about the CSR, they always think it is the responsibility of corporate. Even when people talk about the environmental problems, they think the corporate is the real trouble maker of these problems. Of course, corporate should take more social responsibilities, but it is not the only social responsibility taker. In the progress of CSR realization, our government, investors and other stakeholders should take their own responsibility too. That is to say, all the market players, when they make profit or buy something for consumption, should take social responsibilities for their profit or consumption behaviors.

-What is the purpose of CSR?

With the development of human life, people concern more about the quality of life than the quantity of things. The definition of CSR talks about the need of people for the life quality, and it reflects the improvement of their life knowledge.

-Is CSR a cost or investment?

At the end of last century, many corporate owners always treat CSR as one cost of their corporate. However, this attitude is changed now. For one corporate and for the short period, CSR is the cost of corporate. But, CSR is the investment for the better and higher life quality. So from the aspect of the whole social interest, CSR is really an investment.

-Is the profit positive, negative or 0 ?

When scholars treat CSR as the investment, some corporate owners may ask whether the profit of CSR is positive, negative or 0 . In fact, the profit of CSR cannot be calculated in the general project ways, because CSR is the basic requirements for human survival. So for the short-term, the profit of CSR maybe negative, but for the long term, the profit of CSR should be positive. 


\section{The significance of the realization mechanism}

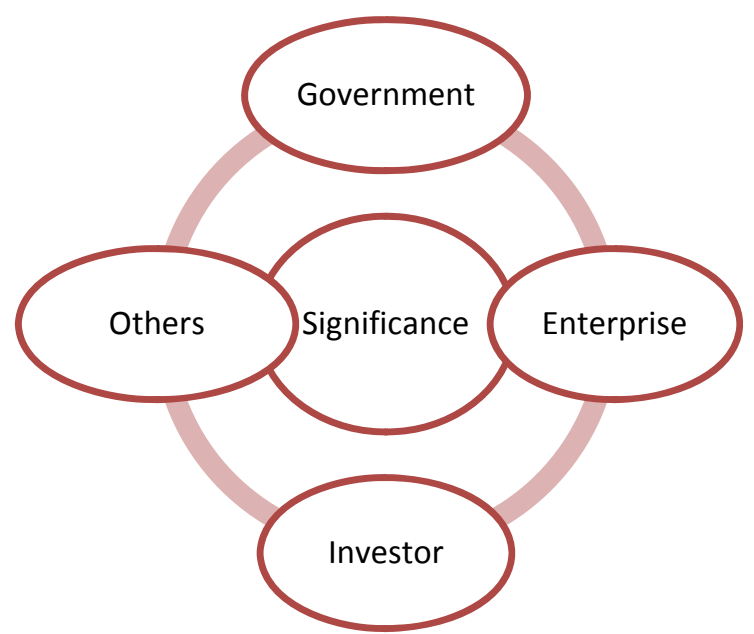

Figure 3. the significance of CSR realization mechanism

\section{-For the government}

To help to solve the environmental problems, food safety problems is the responsibility of government management, and the government should try its best to guarantee the food and environment safety. The realization mechanism not only can help government to realize the management function, but also can help to reduce the cost and energy of government on the such problems.

-For the corporate

The realization of CSR is a popular social theme, but it cannot be realized by one or two corporate. To build one excellent realization mechanism can motivate the corporate to take its own responsibility, and can help corporate to take social responsibility easier and reduce more cost to realize CSR. At the same time, the realization mechanism can avoid the phenomenon that some corporate don't want to take their social responsibilities.

\section{-For investors}

When investors in the capital market want to find some investment projects, they should think about the performance of CSR, that is to say, the investors in the capital market should make CSR investment. CSR investment can help the investors to protect their own interest, but also can supervise the corporate to take CSR. One better realization mechanism can help the investors in the market to invest better. At the same time, the corporate with better performance on CSR will attract more investment in the capital market.

-For the other stakeholders

The environmental and food problems concern the interest of the whole society including other stakeholders. The better realization mechanism can provide a better living environment and safe food for the human being. All these reflect the interest of the other stakeholders.

The realization mechanism based on SPRE framework

\section{The basic framework of realization mechanism}

The realization mechanism of this paper is a mechanism that supervises and helps corporate to take the social responsibility. It can provide a way to make corporate take social responsibility more easily, and also provide a way to help the government and other stakeholders to take part in the realization of CSR and to supervise the corporate to take CSR. This long term mechanism includes 
the function of law and supervision by the government, the operation decision by the corporate, the investment decision by the capital market and other stakeholders' interest.

From the figure 4, we can see that the SPRE framework of realization mechanism contains four different layers: strategic layer (S), purpose layer (P), Responsibility taker layer (R), and execution layer (E). All these four layers are interrelated to one another. The strategic layer (S) gives the direction of the CSR realization. The purpose layer (P) describes the exact aim of CSR realization. The realization taker layer $(\mathrm{R})$ is the executive and bearer of the CSR realization. And the execution layer (E) gives the detailed policy and tactics for the CSR realization. All the four aspects form the SPRE framework of the CSR realization mechanism, and this mechanism is a closed circle. This circle tells us that the realization of CSR cannot be done in short term, but it can be improved by the finish of one circle.

Once the CSR strategy is given by the whole society, it will be divided into several CSR aims, and these aims will be realized through many types of policies, tactics and programs by all the responsibility takers to realize the CSR strategy. When the strategy of CSR is realized, another new CSR strategy will occur. So the realization mechanism of CSR is a circle. And the whole detail can be described in the figure 4 .

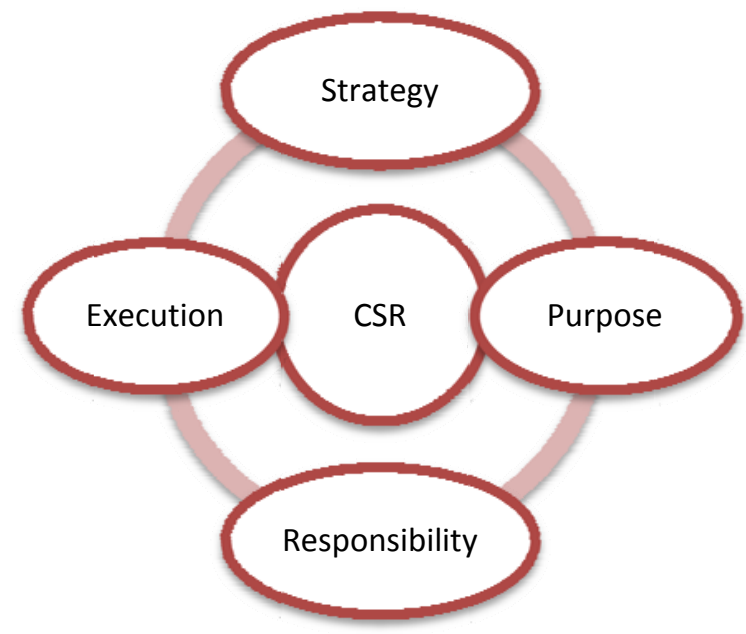

Figure 4. The basic SPRE framework of CSR realization mechanism

\section{The concrete implement of SPRE framework}

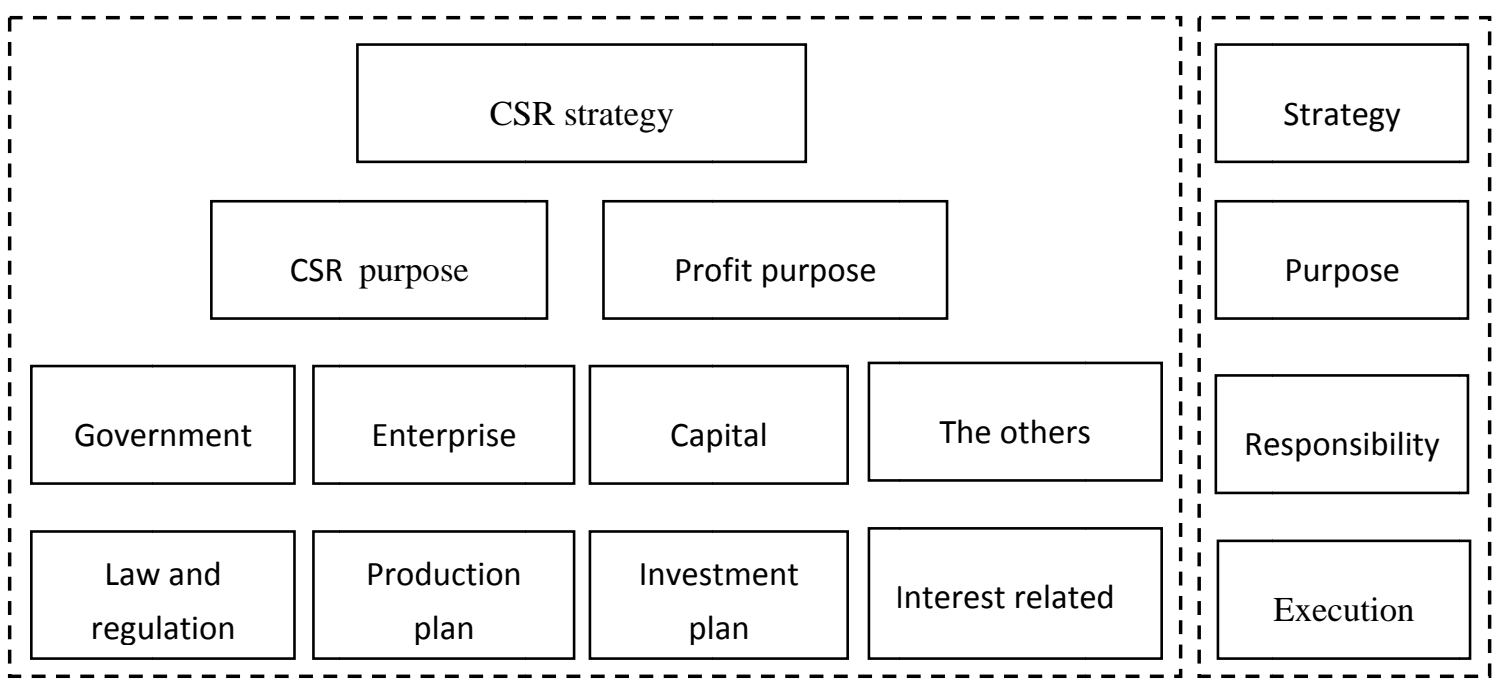

Figure 5. the concrete implement of CSR realization mechanism 
The figure 5 gives us the detailed concrete implement of SPRE framework in the realization mechanism of CSR. From this SPRE framework, we can learn the whole detail of the realization of CSR.

Strategy layer (S): It is the overall objective layer of CSR, and it reflects the overall life requirement of human being, the development of the nation. The strategy made by the government is related to the performance of the CSR realization. The better designed CSR strategy can motivate corporate and other main market payers to take social responsibility, and can improve the quality of human life.

Purpose layer (P): The purpose layer is the decomposition of the CSR strategy. One better designed CSR purpose should not only concern about the purpose of CSR realization, but also the purpose of the corporate profit. The purpose of CSR focuses on the interest of the whole society, the quality of the human life. And the sustainable development of human being needs material which is provided by the corporate. The traditional idea think that the corporate only focuses on its own profit, but the modern corporate theory is that the corporate is the creator the society wealth. The profit of the corporate is the material base for the realization of CSR. The CSR purpose and the corporate profit purpose are related to each other. If we only focus on the CSR purpose and care nothing about the corporate profit purpose, for the long term, the corporate cannot survive and the CSR realization mechanism will have no material base. On the contrary, if the corporate only pay attention to the corporate profit, and pay no attention to the CSR, the whole environment will be destroyed and human being cannot survive.

Responsibility taker layer (R): This layer talks about the takers of CSR. Corporate is the main taker of CSR in the CSR realization, however, other takers should take their own responsibilities. The government should make policy, rule and regulation to help all the takers to take CSR. The other stakeholders should take the responsibility for the sustainable development of the whole society.

Execution layer (E): This layer is the implement of the law, rule and regulation, and action taken by the CSR takers. Of course, this layer also concerns on the deal with the problems in the realization mechanism.

\section{The game progress of SPRE framework}

\begin{tabular}{|c|c|c|c|c|c|c|}
\hline Premise & \multicolumn{3}{c|}{ Toundation } & & Result \\
\hline $\begin{array}{c}\text { Positive Sum Game } \\
\text { Zero Sum Game } \\
\text { Negative Sum Game }\end{array}$ & $\longrightarrow$ & Cooperation & & Pareto Improvement & $\longrightarrow$ & Pareto Optimality \\
\hline
\end{tabular}

Figure 6. the gaming progress of CSR realization mechanism

Game theory can be divided into cooperation game and non-cooperation game according to whether the game sides can get agreement. Under the SPRE framework of CSR realization mechanism, all the takers have their own choices. According to their choices, the gaming results can be positive, negative or 0 .

From the figure 6, the concrete implement of the SPRE framework of CSR realization mechanism contains four parts: the former theory, the base, tactics and result.

The CSR realization mechanism based on SPRE framework firstly concerns about the former theory, and all the responsibility takers have two choices: cooperation or non-cooperation. This result in two games: cooperation game and non-cooperation game. According to the real situation of cooperation, the gaming result can be positive, negative or 0 . 
In fact, in the progress of CSR realization based on the SPRE framework, all the responsibility takers have no other choices but to cooperate. The realization of CSR is really a huge social project, and it cannot be realized by one or several corporate. So all the taker should work together to form a resultant force to realize the CSR. The CSR realization mechanism based on the SPRE framework is a long-term framework, because CSR is talking about the long term sustainable development of human being.

If all the responsibility takers can cooperate very well, we can get Pareto Improvement, and at last we can come to the Pareto Optimality. At that time, CSR has already been realized.

\section{Conclusion and discussion}

CSR has been recognized by the whole society, and the importance of CSR is also not doubtable. However, there are still several issues without conclusions, for instance, the realization of CSR, the takers of CSR. This paper is the first time to look for one CSR realization mechanism based on SPRE framework. This framework contains four layers: strategy layer, purpose layer, responsibility taker layer and execution layer.

Through these four layers, the government, corporate, investor and other stakeholder will cooperate for the long term. This mechanism can help to motivate the realization of CSR, and provide a easy way to take responsibility. However, there are still some problem that should pay more attentions, such as the responsibility of government to make law, policy and regulation. This is the further research for me.

\section{Literature}

[1] Friedman, Milton. "The social responsibility of business is to increase its profits." Corporate ethics and corporate governance. Springer berlin heidelberg, 2007. 173-178.

[2] De George, R. T. (2011). Business ethics. India: Pearson Education Press.

[3] Chell, E. (2007). Social enterprise and entrepreneurship towards a convergent theory of the entrepreneurial process. International small business journal, 25(1), 5-26.

[4] Intriligator, M. D. (2004). Globalization of the world economy: Potential benefits and costs and a net assessment. Journal of Policy Modeling, 26(4), 485-498.

[5] Maohua, L., \& Zéman, Z. (2016). Study on the SRID evaluation framework of agricultural enterprises in China. Visegrad journal on bioeconomy and sustainable development, 5(1), 36-40.

[6] Maohua, L., \& Zéman, Z. (2016). The application of AHP in SRID evaluation framework of Chinese agricultural enterprise. Hungarian agricultural engineering, 30(2), 17-27. 